\title{
Visualization of Purkinje Neurons of Hypothyroid Brain under Golgi Cox Stain
}

\author{
Mariyah Hidayat ${ }^{1}$, Inayatullah Khan ${ }^{2}$, Tahira Hassan ${ }^{3}$, Shire Chaudhry ${ }^{4}$, Khalid P.Lone ${ }^{5}$
}

\begin{abstract}
Background: Golgi staining was invented hundreds of years ago but it is still a reliable method to study the anatomy of neurons. Objective: This experiment was conducted to study the structure of Purkinje neurons of cerebellum of neonate rats born from hypothyroid dams under golgi cox stain and compare it to the control group.

Material and Methods: For this purpose 10 female wistar rats were divided equally into 2 groups control (A) and hypothyroid (B) groups and allowed to conceive. For inducing hypothyroidism in dams, Propylthiouracyl (PTU) was administered in a dose of $15 \mathrm{mg} / \mathrm{kg} / \mathrm{day}$ orally mixed with chow daily a week before mating and throughout the period of gestation and weaning uptil $22 \mathrm{nd}$ day after delivery. On the $23^{\mathrm{rd}}$ day, 10 neonatal rats from each group were sacrificed and blood samples were immediately collected for evaluating serum levels of T3, T4 and TSH. The freshly extracted brains were placed in Golgi Cox solution in complete darkness for 18 to 21 days and the solution was changed every alternate day. The brains were then removed from this stain, processed, infiltrated with parafin, cut into $80 \mu \mathrm{m}$ thick sections by a microtome and mounted on gelatin coated slides, which were now incubated in $20 \%$ ammonium hydroxide for ten minutes. They were then washed in distilled water for 2 minutes and passed through ascending ethanol series $70 \%, 95 \%, 100 \%$ (five minutes each) and two times xylene (10 minutes each). The sections were now coverslipped, visualized and photographed under a research microscope.

Results: Serum enzyme analysis revealed that group PP pups had significantly increased serum levels of TSH and control CC pups showed normal levels of this hormone. T3 and T4 levels were not significantly altered. The number of dendrites seen in purkinje neurons were less in group PP as compared to CC. Normal Purkinje cell count in both the groups were not significantly variable, but the apoptotic cells were significantly more in PP group.

Conclusion; Hypothyroidism decreases the number of dendrites ofpurkinje neurons in cerebellum, causing impaired neuronal connectivity.
\end{abstract}

Key Words: Hypothyroidism, Golgi Cox Stain, Purkinje neurons, cerebellum, propylthiouracyl.

This article may be cited as: Hidayat M, Khan I, Hassan T, Chaudhry S, Lone K.P

Visualization of Purkinje neurons of hypothyroid brain under Golgi Cox Stain. J Saidu Med Coll Swat 2020;10(1):03-07

\section{INTRODUCTION}

Thyroid Hormones (THs) are essential for the growth of fetal and neonatal brain as well as for many other phases of pregnancy and fetal growth ${ }^{1}$. The fetus has two potential sources of THs - its own thyroid and the thyroid of its mother'. Human fetuses are able to synthesize THs at roughly 12 weeks of gestation ${ }^{3}$. In rats, the total T4 and T3 concentrations is detected from $18^{\text {th }}$ gestational day because by that time, the fetal thyroid gland is mature enough to synthesize its own thyroid hormones ${ }^{4}$. Hypothyroidism in either the mother or fetus can have dire consequences, including a high incidence of mental retardation ${ }^{5}$.

Cerebellum regulates and co-ordinates motor activities of the brain. It monitors many motor functions in co-ordination with cerebral cortex ${ }^{6}$. The cortex of the cerebellum is composed of 3 layers when viewed under a light microscope - the molecular layer, Purkinje layer and Granular layer.

1.Department of Anatomy, Rahbar Medical and Dental College, Lahore. 2.Department of Anatomy, Saidu Medical College, Saidu Sharif, Swat. 3.Department of Oral Biology, University of Health Sciences, Lahore

4.Ziauddin Medical University, Karachi

5.Department of Physiology \& Cell Biology, University of Health

Sciences, Lahore.

Correspondence: Professor Dr. Mariyah Hidayat

Department of Anatomy, Rahbar Medical and

Dental College, Lahore.

Email: drmariyah.hidayat@gmail.com
Purkinje neurons are found within the Purkinje layer and they are some of the largest motor neurons in the human brain, with a complicatedly decorative dendritic tree, containing a large number of dendritic spines ${ }^{7}$. The Purkinje cell neurons appear in a single layer and are fundamentally important in the developing cerebellum $^{7}$. The position and number of the Purkinje cells are essential for the formation of synaptic connections in the molecular layer with the granule cells ${ }^{8}$.

Although the THs have a wide distribution of receptors at the level of cell membrane and nucleus, majority of its actions are exerted through the binding of T3 to nuclear thyroid hormone receptors ${ }^{9}$. In humans, T3, T4 and thyroid receptors are already present within the developing cerebellar cortex even before the functioning of fetal thyroid gland activity during $12^{\text {th }}$ week of intrauterine life, which suggests an important role for maternal $\mathrm{TH}$ during this critical period of brain development ${ }^{7}$. In the Purkinje cells, TRa is the first isoform to be detected, however, after the second postnatal week TR $\beta$ is predominantly expressed ${ }^{10}$. 
THs are necessary for proper central nervous system development, and they have long been known to regulate neuronal differentiation and migration, synaptogenesis, and myelination ${ }^{11}$. This is the reason why a child with congenital hypothyroidism has structural impairment of motor neurons.

The cerebellum is located behind the brain stem and it was one of the first targets of THs to be identified $^{6}$. It is a useful model for studying the mechanisms by which THs influences the motor activities of brain. In particular, the cerebellum has a relatively homogenous and simple structure with a well-characterized laminar organization and a small number of cell types that develop within defined regions ${ }^{10}$.

The major defect in the cerebellum of hypothyroid rats involves the Purkinje cells ${ }^{12}$. Both the position and number of the Purkinje cells are normal, but they have a stunted dendritic tree ${ }^{7}$. As a result, the Purkinje neurons cannot establish a normal number of synaptic contacts with the neighbouring neurons and a permanent impairment of neuronal connectivity results. These abnormalities can be reversed if treatment with $\mathrm{TH}$ is given before the critical period of cerebellar development, i.e., before twenty one days of age in the rat ${ }^{7}$.

Golgi staining was invented hundreds of years ago but it is still a reliable method to study the anatomy of neurons. Golgi-Cox is accepted as the ideal method for guaranteeing the staining of entire dendritic trees of neurons, since it gives consistent and well-ordered saturation of neuronal processes. It stains dendrites black and leaves a very clear background. This experiment was designed to observe the morphology of purkinje neurons of cerebellum under both normal and hypothyroid state in neonatal Wistar rats.

\section{MATERIALAND METHODS}

This experiment was conducted in the Animal House and Department of Anatomy of University of Health Sciences (UHS), Lahore, after obtaining ethical approval from committee on the Ethics of Animal Experiments for medical research at UHS, in accordance with the recommendations and guidelines of the committee.

Ten female Wistar rats in good health, 12-16 weeks old \& weighing between $210-230$ grams, were divided equally into two groups a week before mating. Group CC was labelled as control group and received plain drinking water and chow. Group PP was made hypothyroid by receiving $15 \mathrm{mg} / \mathrm{kg} /$ day of PTU mixed with chow orally daily a week before mating and throughout the period of gestation and weaning uptil 22nd day after delivery. The neonates were sacrificed on $23^{\text {rd }}$ postnatal day, their blood extracted directly from the heart and serum total T3, T4 and TSH measured.

The brains were removed from the skull as quickly as possible but handled carefully to avoid damage or pressing of the tissue. They were rinsed quickly in double distilled water to remove blood from the surface. Each brain was cut roughly into 3 equal parts horizontally. The tissue was immersed in 4\% paraformaldehyde for 24 hours.

Solutions $A$, B and $C$ were prepared 3 days before sacrificing the animals according to the protocol given by Levine et al $(2012)^{13}$. Solution A comprised of $5 \%$ Potassium Dichromate Solution, prepared by dissolving 5 grams potassium dichromate powder into $100 \mathrm{ml}$ of hot deionized distilled water. Solution B contained 5\% Mercuric Chloride Solution, prepared by dissolving 5 grams of mercuric chloride powder into $100 \mathrm{ml}$ of hot deionized distilled water. Solution C contained 5\% Potassium Chromate Solution, prepared by dissolving 5 grams of potassium chromate powder into $100 \mathrm{ml}$ of cold deionized distilled water. After preparation of these three stock solutions the method adopted by Levine et al in $2012^{13}$ was followed stepwise; $100 \mathrm{ml}$ of solution A was added to $100 \mathrm{ml}$ of solution B. Then $200 \mathrm{ml}$ of distilled water and $80 \mathrm{ml}$ of solution $\mathrm{C}$ were added together. The solution A-B mixture was now slowly poured into the diluted solution $\mathrm{C}$, while constantly stirring. When mixed thoroughly and correctly, a red-yellow precipitate was formed. This was the Golgi-Cox solution. It was stored in the dark for 3 days and later filtered before use.

After preparation and filtration of this solution, the brains were immersed in it in complete darkness for 18 to 21 days. This solution was changed every alternate day. The brains were then removed from this solution using blotting paper, dehydrated in $50 \%, 70 \%$, two changes of $95 \%$ alcohol for 4 hours each. Later the brain tissue was placed in xylene for two hours and then transferred to parafiin wax and enclosed within this wax in the shape of a block. These blocks were cooled and 
cut into $80 \mu m^{14}$ thick sections with the help of a microtome and mounted on gelatin coated slides which were allowed to air dry for 24 - 48 hours. They were now washed with Tris buffered saline. Almost all the work performed on this stain in the past has been done by slicing the sections under a vibratome but this experiment was the first of its kind where a microtome was used instead for cutting the sections.

The slides were now incubated in $20 \%$ ammonium hydroxide for ten minutes. They were then washed in distilled water for 2 minutes and passed through descending ethanol series $70 \%, 95 \%$, $100 \%$, five minutes each, and two times xylene, for 10 minutes each. The sections were mounted with DPX, coverslip applied, visualized and photographed under a research microscope. For counting of cells, a magnification of $100 x$ was applied. A grid was placed in eyepiece and calibrated. The cells visible with a normal sized cell body and a visible dendrite pointing from one end were defined as normal and healthy whereas those with distorted or shrunken bodies, the cells were defined as apoptotic. Data are expressed as mean \pm S.D by using One way Anova

\section{RESULTS}

When the mean serum levels of TSH were measured, it was observed that PP group had significantly raised levels of this hormone (Table1-A) as compared to CC group, and serum T4 levels were slightly decreased in PP group, but no significant decrease was observed between both the groups in T3 serum levels (Table 2).

The slides were visualized under a research light microscope in the power field of $10 x$ magnification. Although the dendritic tree could not be stained completely, but it was observed that the apex of the pyramidal cell from where the dendrite emerged had a prominent dendritic process in the control group (fig.1) when compared to hypothyroid group (fig.2).
Furthermore, it was also observed that the cell outlines and nuclei in control group were well preserved as compared to the hypothyroid group, where they were distorted.

The normal cell count in both CC and PP groups was not significantly variable, but less number of apoptotic cells were visualized in control group as compared to hypothyroid group.

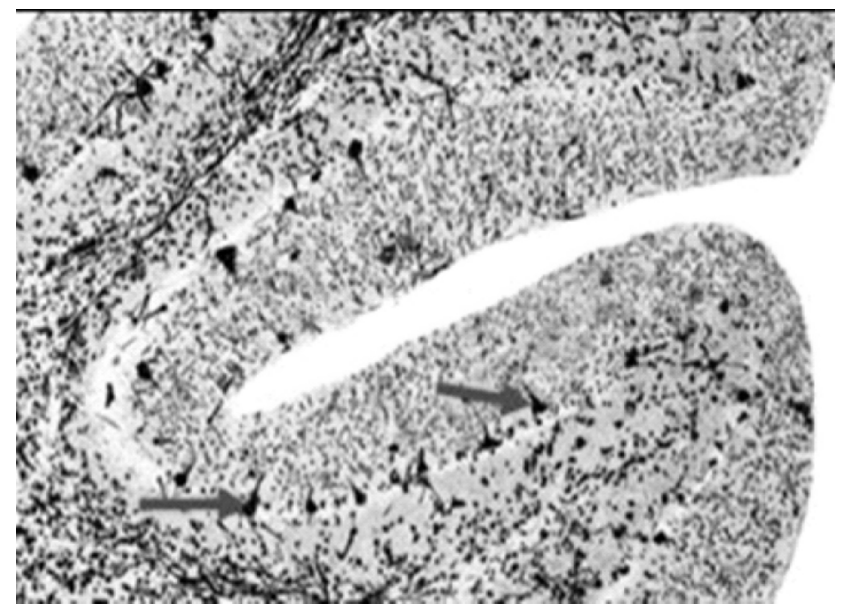

Fig.1. Group CC (control); Purkinje cells with apical dendrite (arrow) observed under 10x magnification in golgi-cox stained slide.

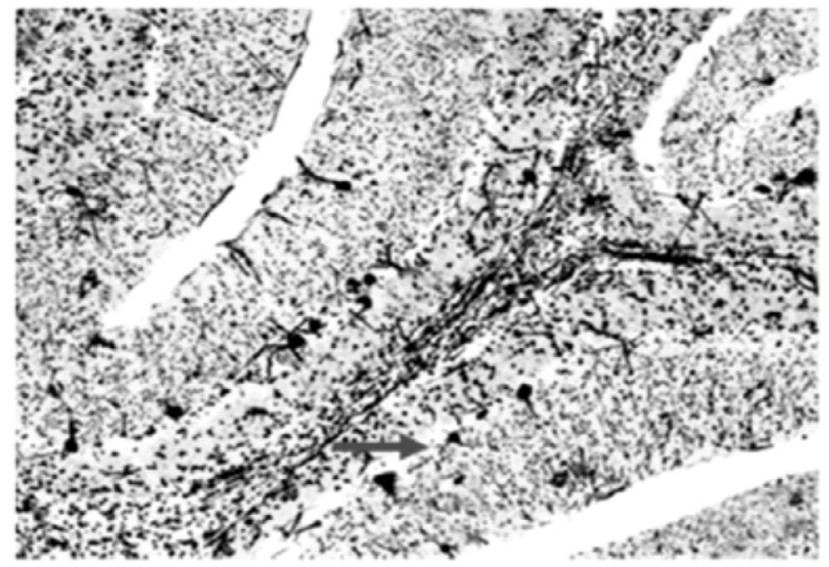

Fig.2. Group PP (hypothyroid); A shrunken Purkinje cell seen with no morphological details under 10x magnification in golgi-cox stained slide.

Table 1- A. Mean values of TSH, T3 and T4 in all the groups.

\begin{tabular}{|c|c|c|c|}
\hline Groups & TSH (ng/dl) & T3 (ng/dl) & T4 (ng/dl) \\
\hline CC & $11 \pm 2.6$ & $35.7 \pm 2.5$ & $37.3 \pm 4$ \\
\hline PP & $22 \pm 4.5^{*}$ & $32.7 \pm 1.5$ & $33.3 \pm 4$ \\
\hline
\end{tabular}


Fig 1: Statistical analysis of the effects of PTU on the Purkinje cells in Cerebellum.

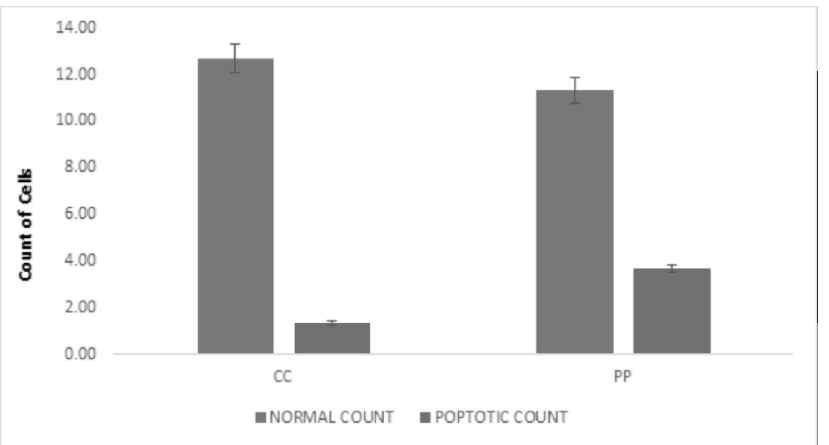

The data were expressed as mean $\pm S D(n=9)$. CC: control, PP: treated with PTU,. There was a significant difference between the apoptotic cell count in both the groups $(P<0.05)$, whereas the difference in the number of apoptotic cells in CC (1.3 mean/unit area ) and PP (3.7 mean/unit area) was significant $(P<0.05)$

\section{DISCUSSION}

This study investigated and compared morphology of Purkinje cells in both control and hypothyroid groups under golgi cox stain. It is well known that in terms of their dendritic arbors, Purkinje cells are the most prominent cell type in the cerebellar cortex ${ }^{10}$.

Rodent cerebellar development is postnatal and completes in the first 3 weeks after birth ${ }^{7}$, when transformation from a smooth cerebellar surface to a lobulated cerebellum is completed. It has long been known that cerebellar morphogenesis is closely linked to $\mathrm{TH}$ regulation, although the underlying mechanisms through which THs control this process remain unclear ${ }^{7}$.

Hypothyroidism results in a number of morphological alterations in the cerebellum, including increased neuronal death within the internal granular layer, defects in granular cell migration, impaired Purkinje cell dendrite formation, delayed myelination and increased cell apoptosis $^{10,15}$. In the present study, deficiency of THs lead to impaired development of Purkinje neurons (fig.2). Although the cells did not take up proper stain, but it was observed in some cells that the main process of dendrite was not developed when compared to the control group (fig.2). In rodents, $\mathrm{TH}$ administration prior to the end of $2^{\text {nd }}$ postnatal week prevented these structural changes.

For this experiment, a microtome was used for tissue sectioning instead of a vibratome, as this equipment was not available. There were many difficulties encountered while running the slides through the series of alcohol and xylene, as the tissue used to come off. Experiments have been conducted highlighting the steps of Golgi staining technique and the difficulties encountered while performing this method ${ }^{16}$. Zaqout and Kandl $(2016)^{17}$ prepared gelatin coated slides in their laboratory which were successful in adhering the tissues to the slides. We followed the same procedure.

This experiment was only meant to study the number and structure of purkinje cells, ignoring the other populations of cells in the cerebellum. Moreover, this stain could not highlight all of the Purkinje cells present, but overall the number of purkinje cells seen in group $B$ were less as compared to group $A$, highlighting the stunted growth of not just the dendrites but also of the Purkinje cell as a whole (fig.2).

Table 2. Mean normal and apoptotic Purkinje cell count (under immunohistochemical stain).

\begin{tabular}{|c|c|c|}
\hline Group & $\begin{array}{l}\text { Mean Normal Purkinje } \\
\text { cell count (per unit area) }\end{array}$ & $\begin{array}{l}\text { Mean Apoptotic Purkinje } \\
\text { cell count (per unit area) }\end{array}$ \\
\hline CC & 12.7 & 1.3 \\
\hline PP & 11.3 & 3.7 \\
\hline
\end{tabular}




\section{CONCLUSION}

Hypothyroidism decreases the number of dendrites of purkinje neurons in cerebellum, causing impaired neuronal connectivity. It perhaps also decreases the number of Purkinje cells, but more experimental work needs to be done to reach to a final conclusion.

\section{REFERENCES}

1. Pemberton HN, Franklyn JA, Kilby MD. Thyroid hormones and fetal brain development. Minerva Ginecol. 2005 Aug;57(4):367-78.

2. Smallridge RC, Ladenson PW.; Hypothyroidism in Pregnancy: Consequences to Neonatal Health, The Journal of Clinical Endocrinology \& Metabolism, 2001; Vol .86(6): 2349-2353,

3. Soma-Pillay P, Nelson-Piercy C, Tolppanen H, Mebazaa A. Physiological changes in pregnancy. Cardiovasc. J. Afr. 2016;27(2):89-94.

4. Choksi NY., Jahnke St,. Hilaire C, Shelby M. Role of Thyroid Hormones in Human and Laboratory Animal Reproductive Health Birth Defects Research (Part B) 2003; 68:479-491.

5. Berbel P., Navarro D.,Roman GC. An evo-devo approach to thyroid hormones in cerebral and cerebellar cortical development: Etiological implications for autism. Front.Endocrinol. 2014; 5, 14-6.

6. Hull C, Regehr WG. Identification of an inhibitory circuit that regulates cerebellar Golgi cell activity. Neuron. 2012;73(1):149-158.

7. Bernal J. Thyroid Hormones in Brain Development and Function. [Updated 2015 Sep 2]. In: Feingold KR, Anawalt B, Boyce A, et al., editors. Endotext [Internet]. South Dartmouth (MA): MDText.com, Inc.; 2000

8. Masoli S, D'Angelo E. Synaptic Activation of a Detailed Purkinje Cell Model Predicts Voltage-Dependent Control of Burst-Pause Responses in Active Dendrites. Front Cell Neurosci. 2017;11:278.
9. Sinha R, Yen PM. Cellular Action of Thyroid Hormone. [Updated 2018 Jun 20]. In: Feingold KR, Anawalt B, Boyce A, et al., editors. Endotext [Internet]. South Dartmouth (MA): MDText.com, Inc. 2000;

10. Faustino LC, Ortiga-Carvalho TM. Thyroid hormone role on cerebellar development and maintenance: a perspective based on transgenic mouse models. Front Endocrinol (Lausanne). 2014;5:75.

11. Mei L, Nave KA. Neuregulin-ERBB signaling in the nervous system and neuropsychiatric diseases. Neuron. 2014;83(1):27-49.

12. Chatonnet F, Picou F, Fauquier T, Flamant F. Thyroid hormone action in cerebellum and cerebral cortex development. J. Thyroid. Res. 2011;2011:1457-62.

13. Levine ND, Rademacher DJ, Collier TJ,. Advances in thin tissue Golgi-Cox impregnation: fast, reliable methods for multi-assay analyses in rodent and nonhuman primate brain. J. Neurosci. Methods. 2013;213(2):214-227.

14. Risher WC, Ustunkaya T, Singh Alvarado J, Eroglu C. Rapid Golgi analysis method for efficient and unbiased classification of dendritic spines. PLoS One. 2014;9(9):107591.

15. Faustino LC and Ortiga-Carvalho TM. Thyroid hormone role on cerebellar development and maintenance: a perspective based on transgenic mouse models. Front. Endocrinol., 20 May 2014

16. Bayram-Weston Z, Olsen E, Harrison DJ, Dunnett SB, Brooks SP. Optimising Golgi-Cox staining for use with perfusion-fixed brain tissue validated in the zQ175 mouse model of Huntington's disease. J. Neurosci. Methods. 2016;265:81-88.

17. Zaqout, S., and Kaindl, A. M. Golgi-Cox staining step by step. Front. Neuroanat. 2016; 10:38. 